\title{
Treating depression in HIV-positive patients affects adherence
}

\author{
M Y H Moosa, F Y Jeenah
}

\author{
Division of Psychiatry, Faculty of Health Sciences, University of the Witwatersrand, Johannesburg \\ M Y H Moosa, FC Psych, MMed Psych, MFGP, MB ChB \\ F Y Jeenah, FC Psych, MMed Psych, MB ChB
}

Corresponding author: M Y H Moosa (yusuf.moosa@wits.ac.za)

Aim. To determine changes in adherence to antiretroviral therapy (ART) in HIV-positive patients with depression, following treatment with an antidepressant or psychotherapy.

Methods. The study was prospective, randomised and controlled. Consenting volunteers aged $\geq 18$ years and stable on ART for $\geq 6$ months were included in the study. Sociodemographic data were obtained, and a clinical diagnostic evaluation and the Hamilton Depression rating scale (HAMD) were performed on all subjects at entry to and at the end of the study. Participants found to be depressed were randomly assigned antidepressant treatment (20 mg citalopram) or interpersonal psychotherapy (IPT) (5 sessions). Medication was dispensed at each visit and patients were asked to return all unused medication to determine ART adherence. The study was approved by the University of the Witwatersrand.

Results. Sixty-two HIV-positive persons receiving ART participated; 30 were not depressed (control group) and 32 were depressed (patient group). No significant differences in demographic characteristics existed between the control and patient groups. Mean ART adherence at the start of the study was $99.5 \%$ (standard error (SE) \pm 0.46 ) and $92.1 \%$ ( $\mathrm{SE} \pm 1.69$ ) in the control and patients groups, respectively. Mean ART adherence at the end of the study changed marginally in the control group (99.7\%; SE \pm 0.46 ) and increased significantly in the patient group (99.5\%; SE \pm 0.13) $(p>0.05)$. The mean ART adherence rate of patients who received pharmacotherapy increased from $92.8 \%$ to 99.5\%, and of those who received psychotherapy increased from $91.1 \%$ to $99.6 \%(p>0.05)$. There was no significant association between the increased adherence in the patient group and baseline demographic and clinical characteristics, irrespective of antidepressant therapy or IPT $(p>0.05)$.

Conclusion. Successful treatment of depression with an antidepressant or psychotherapy was associated with improved ART adherence, independent of the type of treatment and sociodemographic factors. It is necessary to identify HIV-positive patients at risk of depression, to initiate antidepressant treatment which may prevent ART non-adherence, and subsequent disease progression and increased morbidity.

S Afr J HIV Med 2012;13(3):144-149. DOI:10.7196/SAJHIVMED.782
The Joint United Nations Programme on HIV and AIDS recently reported that the number of people newly infected with HIV and the number of AIDS-related deaths are decreasing globally. ${ }^{1}$ The programme reported that an estimated 2.6 million people were newly infected with HIV in 2009, representing a 20\% drop from the 3.1 million people infected in 1999. In South Africa (SA), the estimated HIV prevalence among all age groups was 10.6\% (5.2 million people) in 2008. ${ }^{2}$ Although the prevalence in SA has stabilised in recent years, it is still significantly higher than in most countries in sub-Saharan Africa and the rest of the world. Studies have also reported a high prevalence of co-morbid depression among HIV-positive individuals (5 $48 \%)^{3-9}$ These variable rates of depression may be explained by variations in the actual populations studied (age, sex, education and ethnicity), different study designs, and differences in the stages of HIV/AIDS.

Adherence refers to the willingness and ability of patients to follow health-related advice, take medication as prescribed, attend scheduled appointments, and complete recommended investigations. Actual adherence to treatment in most chronic diseases varies between $33 \%$ and $80 \%{ }^{10,11}$ however, the unique characteristics of HIV necessitate near-perfect adherence to antiretroviral therapy (ART). ${ }^{12-18}$ Reportedly, ART adherence rates of $90-100 \%$ are required to: ensure suppression of viral replication; ${ }^{12,19,20-22}$ maintain CD4 cell counts; prevent clinical progression to AIDS; and prevent the development of ART drug resistance and resistant HIV strains,,$^{10,23-28}$ which could leave drug-naive patients with few effective treatment options.

Although debatable, other reports suggest that complete (100\%) adherence is required to achieve optimal benefits and to prevent virus mutation to treatment-resistant strains. ${ }^{29-31}$

Depression is reported to be one of the major risk factors affecting ART adherence in HIV-positive patients, ${ }^{32-35}$ attributed to a passive ${ }^{36}$ or fatalistic-resigned coping style and hopelessness. ${ }^{37,38}$ ART adherence is lower in depressed HIV-positive individuals compared with non-depressed individuals. There are published data indicating that treatment for depression is associated with improved adherence. ${ }^{39,40}$ However, there is not yet sufficient prospective evidence to support this.

This study, conducted in 2008 at the Perinatal HIV Research Unit (PHRU) of the University of the Witwatersrand, examined ART adherence in a group of HIV-positive patients with depression at Chris Hani Baragwanath Academic Hospital. 
The PHRU receives referrals from antenatal clinics for patients who test HIV-positive, and their partners, for initiation of ART. The primary objective was to determine whether any changes in ART adherence resulted following treatment with an antidepressant or interpersonal psychotherapy (IPT).

\section{Methods}

The study was prospective, randomised and controlled, and sampling was convenience sampling (as it included patients attending the HIV clinic). Volunteers aged $\geq 18$ years were included in the study. All patients were stable on ART for at least 6 months to reduce any confounding effects of the ART on mood and immunity. Subjects were excluded if they: met the Diagnostic and Statistical Manual of Mental Disorders (4th ed.) (DSM-IV) criteria for any other psychotic, mood or substance abuse disorder; were pregnant or nursing; or were medically ill (HIV wasting syndrome, or onset of new opportunistic infections within the preceding 6 weeks). Sociodemographic data were obtained at entry to the study. A clinical diagnostic evaluation and the Hamilton Depression rating scale (HAMD) were performed on all subjects at entry to and end of the study. The depressed patients were randomly assigned to receive either an antidepressant (10 - $20 \mathrm{mg} /$ day citalopram) or IPT. Five IPT sessions were administered during the study period according to the Comprehensive Guide to Interpersonal Psychotherapy. ${ }^{41}$ These guidelines are clear, easily digested, highly informative, and illustrate the application of a conceptual model in the treatment of depression. While we were not trained or experienced in conducting IPT, it is our opinion that the therapy was correctly administered according to the aforementioned guidelines; there were, however, no objective measures to ensure this, signalling a limitation of our study. Adherence was determined by using the patient self-report (number of doses missed in the preceding 3 days) and the pill count (medication was dispensed at each visit and patients were asked to return all unused medication, which was counted by the investigator).

All participants gave written informed consent to participate. The study was approved by the Committee for Research on Human Subjects, University of the Witwatersrand. In addition to their regular follow-up visits, patients were required to make 2 other visits for which they received financial assistance for travel costs. ART and antidepressant drugs were supplied by the district mental-health clinics.
Descriptive statistics were computed as means and frequencies. The 2 -sample $t$-test was used to compare continuous characteristics (age) between the groups. Comparisons of change in adherence as a response to treatment were made between these 2 groups (antidepressant v. psychotherapy). Associations with sociodemographic variables were examined with the use of contingency tables (chi-square test with Yates correction, Fischer's exact test, and odds ratios). All analyses were performed with Statistical Package for Social Sciences (SPSS) software (version 10.0). A $p$-value $<0.05$ was considered significant.

\section{Results}

Sixty-two HIV-positive persons receiving ART participated in the study; 30 were not depressed (control group) and 32 were depressed (patient group).

\section{Sociodemographic characteristics}

In the control group, mean age was 37.7 years (standard error (SE) \pm 1.2 ; range 27 - 51); 88\% were female; $70 \%$ were single (not married, divorced or widowed); 70\% were unemployed despite being able and willing to work; and $83.3 \%$ had achieved a level of education between grade 8 and 12 (Table 1). All control patients disclosed their HIV status to a partner or family member. The majority $(63.3 \%)$ were receiving ART from regimen 1a; $23 \%$ were receiving triomune.

In the patient group, mean age was 36.8 years ( $\mathrm{SE} \pm 1.38$; range 24 - 53); $90.6 \%$ were female; $67.8 \%$ were single (not married, divorced or widowed); $81.3 \%$ were unemployed despite being able and willing to work; and $71.9 \%$ had achieved a level of education between grade 8 and 12 (Table 1). All patients disclosed their status to a partner or family member. Half of the patients were receiving ART from regimen 1a; $15.6 \%$ were receiving triomune.

There were no significant differences between the control and patient groups (receiving pharmacotherapy or psychotherapy) with respect to demographic characteristics, namely: gender ( $\left.\mathrm{chi}^{2}=2.045 ; p=0.359\right)$; marital status; $\left(\right.$ chi $\left.^{2}=0.547 ; p=0.761\right)$; employment status ( $\left.\mathrm{chi}^{2}=5.707 ; p=0.058\right)$; highest level of education ( $\left.\mathrm{chi}^{2}=2.391 ; p=0.664\right)$; number of children ( chi $^{2}=5.022 ; p=0.285$ ); past history of depression $\left(\mathrm{chi}^{2}=4.124 ; p=0.127\right)$; family history of depression $\left(\mathrm{chi}^{2}=2.301 ; p=0.316\right.$ ); or other concurrent medication $\left(\mathrm{chi}^{2}=0.779\right.$; $p=0.677)$ (Table 1).

\section{ART adherence}

At entry to the study, the mean ART adherence was $99.5 \%$ ( $\mathrm{SE} \pm 0.46$ ) in the control group, and 92.1\% ( $\mathrm{SE} \pm 1.69$ ) (95\% confidence interval (CI) 88.65 - 95.53) in the patient group (Fig. 1). At the end of the study, the mean ART adherence in the control group changed marginally to $99.7 \%$ ( $\mathrm{SE} \pm 0.46$ ) (Fig. 1), while in the patient group, the mean adherence increased significantly to $99.5 \%$ ( $\mathrm{SE} \pm 0.13$; CI 99.25 99.78; $p>0.05)$. The mean ART adherence rate of the patients receiving pharmacotherapy increased from $92.8 \%$ to $99.5 \%$, and those receiving psychotherapy increased from $91.1 \%$ to $99.6 \%$ ( $p>0.05$ ) (Fig 2). There was no significant association between this increased adherence rates in the patient group (in those receiving antidepressant medication or IPT) and baseline demographic and clinical characteristics $(p>0.05)$. There was no correlation between the increased adherence rates and changes in HAMD scores.

\section{Discussion}

First-line treatment recommended by the 2010 South African Antiretroviral Treatment Guidelines $^{42}$ for all new adult and adolescent HIV-positive patients is tenofovir, lamivudine and efavirenz/nevirapine (efavirenz is preferred for TB co-infection, and nevirapine is preferred for women of child-bearing age who are not on reliable contraception). Patients who fail on tenofovir-based first-line therapy may be changed to the second-line treatment of zidovudine, lamivudine and ritonavir. The majority of patients in this study were receiving ART in accordance with these treatment guidelines. Approximately 25\% of patients were receiving triomune (a singletablet fixed-dose combination of stavudine, lamivudine and nevirapine) which enhances compliance. No significant differences existed between the control and test groups with respect to the administering of ART or other baseline characteristics. Hence, it is unlikely that any of these factors may have influenced the study's outcomes.

All participants in the patient group had HAMD scores $>15$, indicative of depression. Depression was confirmed clinically by eliciting cognitive and affective symptoms that solely reflect mood state (i.e. anhedonia, depressed feelings, and feelings of worthlessness). Fiftythree per cent of the patients had moderate depression (HAMD score 18 - 24) and $44 \%$ had severe depression (HAMD scores $\geq 25$ ). ${ }^{43}$ All patients responded to treatment - either pharmacotherapy (citalopram) or 
psychotherapy (IPT) - as evidenced by a significant reduction in the mean HAMD scores to $<7$ in both groups. There was no difference between the type of treatment received and changes in mean HAMD scores. These findings are similar to those of other studies utilising pharmacotherapy ${ }^{39,40}$ and psychotherapy, ${ }^{43,44}$ which also report that IPT was more successful than supportive psychotherapy in lessening depression in depressed HIV-positive patients who were not acutely ill.

At entry to this study, mean ART adherence of the non-depressed control group was $99.5 \%$ - much higher than the $50-70 \%$ rate reported in other studies in different social and cultural settings. ${ }^{45-50}$ The higher adherence rate in our study may be attributed to patient attendance at a rollout clinic that enabled regular monitoring and had the staff and resources to support patients as adherence problems emerged.

The study also found that the mean adherence rate, at entry to the study, among the depressed patient group was significantly

Table 1. Sociodemographic characteristics of the control v. depressed patient groups

\begin{tabular}{|c|c|c|c|c|c|}
\hline \multirow[b]{2}{*}{ Characteristics } & \multirow[b]{2}{*}{$\begin{array}{l}\text { Study population } \\
(n=62)\end{array}$} & \multirow[b]{2}{*}{$\begin{array}{l}\text { Controls } \\
(n=30)\end{array}$} & \multicolumn{2}{|c|}{ Patients $(n=32)$} & \multirow[b]{2}{*}{ Significance } \\
\hline & & & $\begin{array}{l}\text { Pharmacotherapy } \\
(n=19)\end{array}$ & $\begin{array}{l}\text { Psychotherapy } \\
(n=13)\end{array}$ & \\
\hline Gender, $n(\%)$ & & & & & $\operatorname{chi}^{2}=2.045 ; p=0.359$ \\
\hline Male & $9(14.5)$ & $6(20)$ & $1(5.3)$ & $2(15.4)$ & \\
\hline Female & $53(85.5)$ & $24(80)$ & $18(94.7)$ & $11(84.6)$ & \\
\hline Marital status, $n(\%)$ & & & & & $\operatorname{chi}^{2}=0.547 ; p=0.761$ \\
\hline Single & $43(69.4)$ & $21(70)$ & $14(73.7)$ & $8(61.5)$ & \\
\hline Married & $19(30.6)$ & $9(30)$ & $5(26.3)$ & $5(38.5)$ & \\
\hline Employment status, $n(\%)$ & & & & & $\operatorname{chi}^{2}=5.707 ; p=0.058$ \\
\hline Employed & $15(24.2)$ & $9(30)$ & $1(5.3)$ & $5(38.5)$ & \\
\hline Unemployed & $47(75.8)$ & $21(70)$ & $17(94.7)$ & $12(61.5)$ & \\
\hline Level of education, $n(\%)$ & & & & & $\operatorname{chi}^{2}=2.391 ; p=0.664$ \\
\hline Grade 0 - 7 & $5(8.1)$ & $2(6.7)$ & $1(5.2)$ & $2(15.4)$ & \\
\hline Grade 8 - 12 & $48(77.4)$ & $25(83.3)$ & $14(73.7)$ & $9(69.2)$ & \\
\hline Tertiary & $9(14.5)$ & $3(10)$ & $4(21.1)$ & $2(15.4)$ & \\
\hline Number of children, $n(\%)$ & & & & & chi $^{2}=5.022 ; p=0.285$ \\
\hline $0-1$ & $23(37.1)$ & $13(43.3)$ & $7(36.8)$ & $3(23.1)$ & \\
\hline$>1$ & $39(62.9)$ & $17(56.7)$ & $12(63.2)$ & $10(76.9)$ & \\
\hline PH of depression, $n(\%)$ & & & & & $\operatorname{chi}^{2}=4.124 ; p=0.127$ \\
\hline Yes & $4(6.5)$ & $1(3.3)$ & $3(9.4)$ & $0(0)$ & \\
\hline No & $58(93.5)$ & $29(96.7)$ & $16(84.2)$ & $13(100)$ & \\
\hline FH of depression, $n(\%)$ & & & & & $\operatorname{chi}^{2}=2.301 ; p=0.316$ \\
\hline Yes & $1(1.6)$ & $0(0)$ & $1(5.3)$ & $0(0)$ & \\
\hline No & $61(98.4)$ & $30(100)$ & $18(94.7)$ & $13(100)$ & \\
\hline ART & & & & & $\operatorname{chi}^{2}=15.68 ; p=0.047$ \\
\hline Regimen $1^{\circ}$ & $35(56.5)$ & $19(63.3)$ & $7(36.8)$ & $9(69.2)$ & \\
\hline Regimen $1 \mathrm{~b}$ & $8(12.9)$ & $1(3.3)$ & $5(26.3)$ & $2(15.4)$ & \\
\hline Triomune & $12(17.9)$ & $7(23.3)$ & $4(21.1)$ & $1(7.7)$ & \\
\hline Other regimens & $7(12.7)$ & $3(10)$ & $3(15.8)$ & $1(7.7)$ & \\
\hline On other medication & & & & & $\operatorname{chi}^{2}=0.779 ; p=0.677$ \\
\hline Yes & $54(87.1)$ & $26(86.7)$ & $17(89.5)$ & $11(84.6)$ & \\
\hline No & $8(12.9)$ & $4(113.3)$ & $2(10.5)$ & $2(15.4)$ & \\
\hline
\end{tabular}




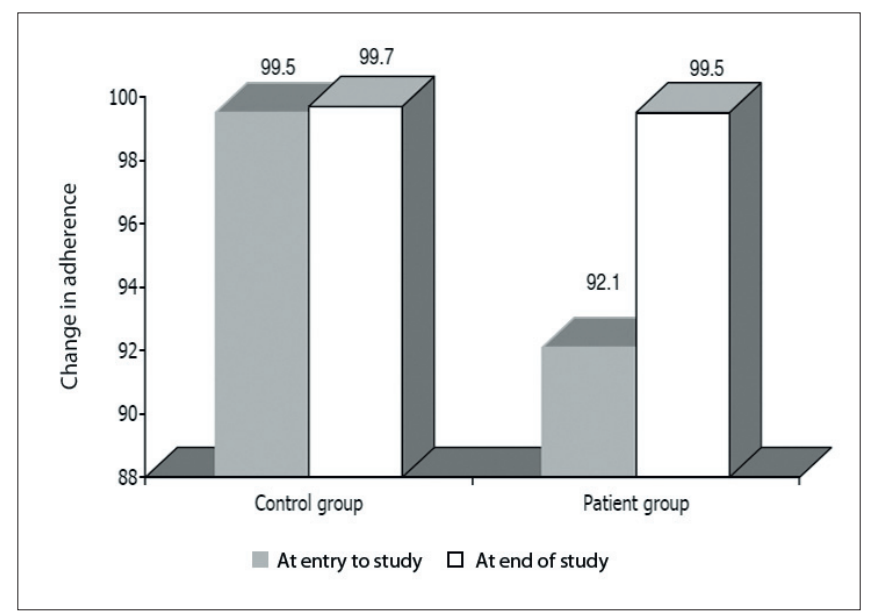

Fig. 1. Changes in ART adherence in the control and patient groups.

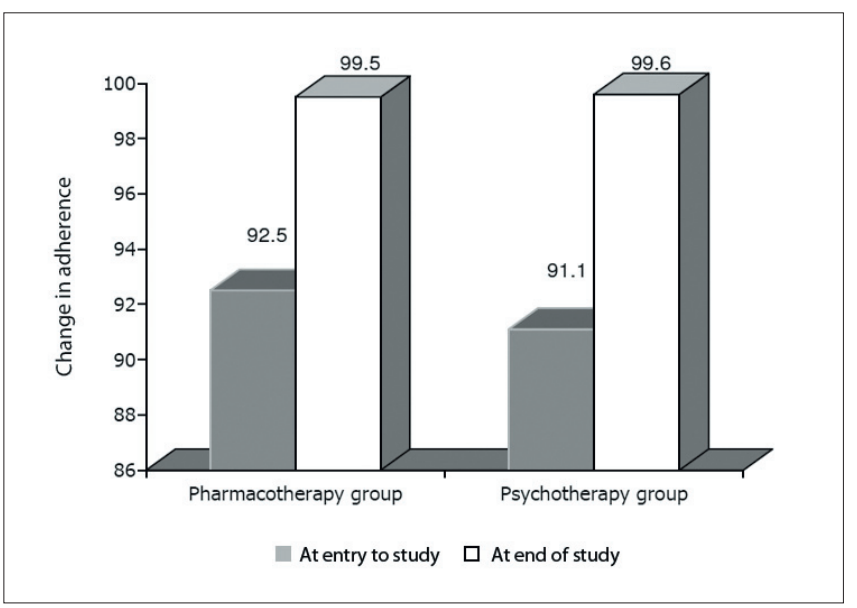

Fig. 2. Changes in ART adherence in the antidepressant v. IPT groups.

lower (92.1\%) than that of non-depressed control group. As previously discussed, studies have reported that depression is a risk factor for non-adherence to highly active ART. ${ }^{32-35}$ Depression is associated with a passive ${ }^{36}$ or fatalistic-resigned coping style and hopelessness ${ }^{37}$ with resultant poor treatment adherence. This study adds support to the findings of the above studies. Furthermore, following 2 months of treatment, the mean adherence rate of the depressed patients increased significantly to $>99 \%$, independent of the type of treatment received (pharmacotherapy or psychotherapy). Other published studies have reported similar improved ART adherence in depressed HIV-positive patients following treatment with an antidepressant or IPT., ${ }^{5,51}$ When medication is used to treat depression, it is important for clinicians to evaluate tolerability and potential adverse effects which may paradoxically decrease adherence. ${ }^{52}$ Selective serotonin reuptake inhibitors (SSRIs) have become widely used in HIV-infected depressed patients because of good tolerability and lack of negative effect on adherence. If, however, adherence is negatively impacted by pharmacotherapy, IPT may be the preferred treatment choice, as it results in increased physical and emotional functioning without tolerability issues. Finally, a combination of both forms of therapy may result in further improved outcomes.

Some researchers question the feasibility of the rapid scaling-up and sustainability of ART programmes in depressed people, ${ }^{25,53}$ citing concerns about the low and suboptimal adherence in depressed patients leading to the development of resistant HIV strains. ${ }^{54-56}$ Resistant strains may leave subsequently infected patients without effective treatment options $^{24}$ or require a change to second-line treatment regimens, which are ten times more expensive than first-line regimens. ${ }^{57}$ On the contrary, the results of our study and others have shown that the onset of depression in HIV-positive patients is negatively associated with ART adherence, and can be significantly improved with treatment. Screening for depression in all ART rollout clinics is essential and HIV-positive patients found to be depressed must be offered ART and treatment for their depression.

Although not considered or evident in our study, many other factors have been reported to negatively affect ART adherence. These factors are commonly divided into 5 intersecting categories: patient variables; treatment regimens; disease characteristics; patientprovider relationships; and clinical setting. ${ }^{59}$ Patient variables include sociodemographic factors (age, gender, race, income, education, literacy and housing status) and psychosocial factors (mental health, substance abuse, family support, religious beliefs about illness and medication, and knowledge and attitude about HIV and its treatment). ${ }^{58-67}$ Studies investigating the role of patient variables as predictors of adherence have largely produced inconsistent results. The tendency to ascribe low adherence to often-deprived social groups is a well-established trend ${ }^{68}$ however, as experience with antibiotics has demonstrated, low adherence is widespread and unpredictable rather than restricted to certain social classes. ${ }^{69}$ Moreover, adherence rates have been shown to vary between individuals and within the same individual over time. ${ }^{59}$

Adherence is therefore best thought of as a variable behaviour rather than a stable characteristic of an individual, and most people will exhibit low adherence some of the time. ${ }^{68}$ Treatment regimen factors include the number of pills prescribed, the complexity of the regimen (dosing frequency and food instruction), the specific type of ART and treatment side-effects. The latter two are associated with sub-optimal adherence, ${ }^{58}$ although experience of symptoms and views about medications may vary according to the type of regimen used. ${ }^{70-72}$ Patient-provider relationship factors include: overall satisfaction and trust in the provider and clinic staff (opinion of the provider's competency, provider's willingness to include the patient in the decision-making process, and compatibility of race/ethnicity between patient and provider); affective tone of the relationship (warmth, openness and co-operation); and satisfaction with the health service (adequacy of referral, availability of transport, general environment and flexibility of appointments). ${ }^{73}$

Methods used to asses adherence fall into 3 categories: subjective measures (self-report, others' report of adherence, and medical chart review); objective measures (pill counts, pharmacy refill records, and use of mechanical or electronic monitors of pill or drug use); and physiological methods or indicators (plasma assay and laboratory reports). ${ }^{15}$ The hierarchy of adherence measures ranks physician and self-assessment reporting as the least accurate, pill count as intermediate and electronic drug monitoring as the most accurate adherence markers. ${ }^{25}$ Each of these measures is associated with certain inaccuracies and implementation difficulties. Pharmacy refill records require that patients always use the same pharmacy. Pill counts require patient co-operation to bring their pills to the requested health visits, and not to share pills. The medication event-monitoring system (MEMS) allows recording of when a drug container is opened via a micro-processor in the cap of the container. However, this requires that patients only remove one dose at a time. Moreover, caps only measure bottle opening and not medication ingestion. The pill count method 
may overestimate adherence compared with MEMS by about $10 \%,{ }^{48,74}$ but still has a higher accuracy compared with structured questionnaires. $^{75}$

The subjective measure of patient selfreport is the most commonly used measure of adherence. In this measure the patient is asked how many doses were missed in the past day, 2 days and 2 weeks or, alternatively, the percentage of prescribed doses taken in the past 4 days. ${ }^{47}$ The format of the questions varies from study to study. Using this measure, inaccuracies may result from use of a longer recall time, in patient forgetfulness and when questioning is imprecise or inconsistent. Further, responses may be influenced by patients' desire to provide a socially acceptable answer, particularly when the interviewer is a health worker whose role has been to exhort the patient to adhere. Nevertheless, self-reported adherence questionnaires are simple and inexpensive and the most widely used method in clinical settings. ${ }^{29,30}$ No single measure of adherence is appropriate for all settings or outcomes; therefore, the use of more than one measure is recommended, as performed in this study, to allow the strength of one method to compensate for the weakness of the other and to determine adherence levels more accurately. ${ }^{76}$

\section{Study limitations}

The relatively small sample size might have hampered statistical comparisons between treatment groups, while the short duration of follow-up might have masked a greater degree of outcomes in both groups. The study was open-labelled, which could have influenced the response to treatment. This was not a population-based study (patients were recruited from the HIV Research Unit); therefore, the results may be biased by the methods of recruitment and enrolment and are not generalisable. Further, an overwhelming majority of the subjects were female; the treatment of HIV-positive men, who face different psychosocial and socio-economic pressures, may have produced different outcomes.

Strengths of the study include the use of more than one adherence measure to reduce inaccuracies. Moreover, comparison of the sociodemographic characteristics did not reveal any substantive differences between the groups.

\section{Conclusion}

The onset of depression in HIV-positive patients is negatively associated with ART adherence. Treatment of this depression with an antidepressant or psychotherapy is associated with significant improvement in ART adherence. Poor adherence leads to ART resistance, which may require a change to a second-line treatment regimen (ten times more expensive than first-line drugs). It is therefore important that healthcare providers identify depression in at-risk patients, to enable closer monitoring and treatment.

Note. This report was part of a large study on HIV and depression. The sociodemographic features of the study population described have previously been reported:

Moosa MYH, Jeenah FY. Antidepressants versus interpersonal psychotherapy in treating depression in HIV-positive patients. South African Journal of Psychiatry 2012;18(2) 47-52.

\section{References}

1. UNAIDS. Global report: UNAIDS Report on the Global AIDS Epidemic 2010. Geneva, Switzerland: UNAIDS, 2010. http://www.unaids. org/documents/20101123 GlobalReport_em.pdf (accessed 5 May 2011).

2. National Department of Health. National Prevalence, Incidence, Behaviour and Communication Survey. Pretoria: Department of Health, 2008. http://www. doh.gov.za/docs (accessed 30 August 2011).

3. Treisman G, Angelino A. Interrelation between psychiatric disorders and the prevention and treatment of HIV infection. Clin Infect Dis 2007;45(4):S313-317. [http://dx.doi.org/10.1086/522556]

4. Lopez AD, Mathers CD, Ezzati M, et al. Global and regional burden of disease and risk factors. Systematic analysis of population health data. Lancet 2006;367:1747-1757. [http://dx.doi.org/10.1016/ S0140-6736(806)68770-9]

5. Yun LWH, Maravi M, KobayashiJS, etal. Antidepressant treatment improves adherence to antiretroviral therapy among depressed HIV-infected patients. J Acquir Immune Defic Syndr 2005;38:432-438. [http://dx.doi. org/10.1097/01.qai.0000147524.19122.fd]

6. Dubé B, Benton T, Cruess DG, et al. Neuropsychiatric manifestations of HIV infection and AIDS. Psychiatry Neurosci 2005;30(4):237-246.

7. Judd F, Komiti A, Chua P, et al. Nature of depression in patients with HIV/AIDS. Aust N ZJ Psychiatry 2005;39(9):826-832. [http://dx.doi.org/10.1111/j.14401614.2005.01659.x]

8. Olley BO, Gxamza F, Seedat S. Psychopathology and coping in recently diagnosed HIV/AIDS patients the role of gender. S Afr Med J 2003;93(12):928-931.

9. Ciesla JA, Roberts JE. Meta-analysis of the relationship between HIV infection and risk for depressive disorders. Am J Psychiatry 2001;158:725 730. [http://dx.doi.org/10.1176/appi.ajp.158.5.725]

10. Goudge J, Ngoma B, Schneider H. Adherence to antiretroviral drugs: Theorising contextual relationships. A review of the adherence and related literature with annotated bibliography. Johannesburg: Centre for Health Policy, University of the Witwatersrand, 2004

11. Paterson D, Swindles S, Mohr J, et al. How much adherence is enough? A prospective study of adherence to protease inhibitor therapy using MEMS caps. 6th Conference on Retrovirus and
Opportunistic Infections, Chicago, IL, USA, 31 January - 4 February, 1999.

12. Singh N, Berman SM, Swindells S, et al. Adherence of human immunodeficiency virus- infected patients to antiretroviral therapy. Clinical Infectious Diseases 1999;29:824-830. [http://dx.doi. org/10.1086/520443]

13. World Health Organization. Adherence and HIV/ AIDS. Geneva, Switzerland: WHO, 2005.

14. Garcia R, Schooley R, Badaro R. An adherence triology is essential for long term HAART success. Braz J Infect Dis 2003;7(5):1-9. [http://dx.doi. org/10.1590/S1413-86702003000500005]

15. Fogarty L, Roter D, Larson S, et al. Patient adherence to HIV medication regimens: a review of published and abstract reports. Patient Educ Couns 2002;46:93-108. [http://dx.doi.org/10.1016/S07383991(801)900219-1]

16. Ammassari A, Trotta MP, Murri R, et al. Correlates and predictors of adherence to highly active antiretroviral therapy: overview of published literature. J Acquir Immune Defic Syndr 2002;31(3):S123-S127. [http:// dx.doi.org/10.1097/00126334-200212153-00007]

17. Parades R. Predictors of virology success and ensuing failure in HIV positive patients starting HAART in Europe. Arch Intern Med 2000;160:1123-1132.

18. Deeks S, Beatty G, Cohen PT, et al. Viral load and $\mathrm{CD}+\mathrm{T}$ cell changes in patients failing potent protease inhibitor therapy. 5th Conference on Retroviruses and Opportunistic Infections, Chicago, IL, 1998.

19. Paterson DL, Potoski B, Capitano B. Measurement of adherence to antiretroviral medications. J Acquir Immune Defic Syndr 2002;31(3):S103-S106. [http:// dx.doi.org/10.1097/00126334-200212153-00003]

20. Hecht FM, Colfax G, Swanson M, et al. Adherence and effectiveness of protease inhibitors in clinical practice. 5th Conference on Retroviruses and Opportunistic Infections, Chicago, Illinois, 1998.

21. Montaner JS, Reiss P, Cooper D, et al. A randomized, double-blind trial comparing combinations of nevirapine, didanosine, and zidovudine for HIVinfected patients. JAMA 1998;279:930-993. [http:// dx.doi.org/10.1001/jama.279.12.930]

22. Vanhove GF, Schapiro JM, Winters MA, et al. Patient compliance and drug failure in protease inhibitor monotherapy. JAMA 1995;276(24):1955-1956. [http://dx.doi.org/10.1001/jama.276.24.1955]

23. Stephenson J. AIDS researchers target poor adherence. JAMA 1999;281:1069. [http://dx.doi. org/10.1001/jama.281.12.1069]

24. Wainberg MA, Friedland G. Public health implications of antiretroviral therapy and HIV drug resistance. JAMA 1998;279:1977-1983. [http:// dx.doi.org/10.1001/jama.279.24.1977]

25. Gill CJ, Davidson HH, Simon JL, et al. No room for complacency about adherence to antiretroviral therapy in sub-Saharan Africa. AIDS 2005;19(12):1243-1249. [http://dx.doi. org/10.1097/01.aids.0000180094.04652.3b]

26. Altice FL, Friedland GH. The era of adherence to HIV therapy. Ann Intern Med 1998;129:503-505.

27. Cohen OJ, Fauci AS. Transmission of multidrugresistant human immunodeficiency virus - the wake-up call. N Engl J Med 1998;339:341-343. [http://dx.doi.org/10.1056/NEJM199807303390511]

28. Mayers DL. Drug-resistant HIV-1: The virus strikes back. JAMA 1998;279:2000-2002. [http://dx.doi. org/10.1001/jama.279.24.2000]

29. Simoni JM, Kurth AE, Pearson CR, et al. Self report measures of antiretroviral therapy adherence: a review with recommendations for HIV research and clinical management. AIDS Behav 2006;10:41-45. [http://dx.doi.org/10.1007/s10461-006-9078-6]

30. Mills EJ, Nachega JB, Buchan I, et al. Adherence to antiretroviral therapy in sub-Saharan Africa and North America: A meta-analysis. JAMA 2006;296:679-690.

31. Kleeberger CA, Phair JP, Strathdee SA. Determinants of heterogeneous adherence to HIV antiretroviral 
therapies in the multicenter AIDS cohort study. J Acquir Immune Defic Syndr 2001;26:82-92.

32. Ammassari A, Antinori A, Aloisi MS, et al. Depressive symptoms, neurocognitive impairment, and adherence to highly active antiretroviral therapy among HIVinfected persons. Psychosomatics 2004;45:394-402. [http://dx.doi.org/10.1176/appi.psy.45.5.394]

33. Starace F, Ammassari A, Trotta MP, et al. Depression is a risk factor for suboptimal adherence to highly active antiretroviral therapy. J Acquir Immune Defic Syndr 2002;31(3):S136-S139. [http://dx.doi. org/10.1097/00126334-200212153-00010]

34. Murphy DA, Wilson CM, Durako SJ, et al. Antiretroviral medication adherence among the REACH HIV-infected adolescent cohort in the USA. AIDS Care 2001;13:27. [http://dx.doi. org/10.1080/09540120020018161]

35. Lucas GM, Cheever LW, Chaison RE, et al. Detrimental effects of continued illicit drug use on the treatment of HIV-1 infection. J Acquir Immune Defic Syndr 2001;71:251-259. [http://dx.doi. org/10.1097/00042560-200107010-00006]

36. Solano L, Costa M, Salvati S, et al. Psychosocial factors and clinical evolution in HIV infection: a longitudinal study. J Psychosom Res 1993;37:39-51. [http://dx.doi. org/10.1016/0022-3999(893)990122-V]

37. Reed GM, Kemeny ME, Taylor SE, et al. Realistic acceptance as a predictor of decreased survival time in gay men with AIDS. Health Psychol 1994;13:299307. [http://dx.doi.org/10.1037/0278-6133.13.4.299]

38. Kalichman SC, Sikkema KJ, Somlai A. Assessing persons with human immunodeficiency virus (HIV) infection using the Beck Depression Inventory: Disease processes and other potential confounds. Pers Assess 1995;64:86-100. [http://dx.doi. org/10.1207/s15327752jpa6401_5]

39. Kirsch I, Deacon BJ, Huedo-Medina TB, et al. Initial severity and antidepressant benefits: A metaanalysis of data submitted to the Food and Drug Administration. PLoS Med 2008;5(2):e45. [http:// dx.doi.org/10.1371/journal.pmed.0050045]

40. Turner EH, Matthews AM, Linardatos E, et al. Selective publication of antidepressant trials and its influence on apparent efficacy. N Engl J Med 2008;358(3):252-260. [http://dx.doi.org/10.1056/ NEJMsa065779]

41. Weissman MM, Markowitz JC, Klerman GL. Comprehensive Guide to Interpersonal Psychotherapy. New York: Basic Books, 2000.

42. National Department of Health. South African Antiretroviral Treatment Guidelines (2010). Pretoria: $\mathrm{DoH}, 2010$

43. Markowitz JC, Klerman GL, Clougherty KF, et al. Individual psychotherapies for depressed HIV-positive patients. Am J Psychiatry 1995;152:1504-1509.

44. Markowitz JC, Klerman GL, Perry SW. Interpersonal psychotherapy of depressed HIV positive outpatients. Hosp Community Psychiatry 1992;43:885-890.

45. Saferen SA, Kumarasamy N, James R, et al. ART adherence, demographic variables and CD4 outcome among HIV-positive patients on antiretroviral therapy in Chennai, India. AIDS Care 2005;17(7):853-862. [http://dx.doi.org/10.1080/09540120500038439]

46. Nemes MIB, Carvalho HB, Souza MFM. Antiretroviral therapy adherence in Brazil. AIDS 2004;18(3):S15-S20. [http://dx.doi. org/10.1097/00002030-200406003-00004]
47. Chesney MA. Factors Affecting adherence to antiretroviral therapy. Clin Infect Dis 2000;20:171176

48. Bangsberg DR, Hecht FM, Charlebois ED, et al. Adherence to protease inhibitors, HIV-1 viral load, and development of drug resistance in an indigen population. AIDS 2000;14:357-366. [http://dx.doi. org/10.1097/00002030-200003100-00008]

49. Reiter GS, Stewart KE, Wojtusik L Elements of success in HIV clinical care: Multiple intervention that promote adherence. Topics in HIV Medicin 2000;8(5):21-30.

50. Mcpherson-Baker S, Malow R, Penedo F, et al. Enhancing adherence to combination antiretrovira therapy in non-adherent HIV-positive men. AIDS Care 2000;12:399-404. [http://dx.doi. org/10.1080/09540120050123792]

51. Lyketsos CG, Hanson A, Fishman M, et al. Screening for psychiatric morbidity in a medical outpatien clinic for HIV infection: The need for a psychiatric presence. Intl J Psychiatry Med 1994;24:103-113. [http://dx.doi.org/10.2190/URTC-AQVJ-N9KG 0RL4]

52. Elliott AJ, Roy-Byrne PP. Major Depressive disorder and HIV-1 infection: A review of treatment trials. Semin Clin Neuropsychiatry 1998;3:137-150.

53. Stevens W, Kaye S, Corrah T. Antiretroviral therapy in Africa. BMJ 2004;328:280-282. [http://dx.doi. org/10.1136/bmj.328.7434.280

54. Carpenter CCJ, Fischl MA, Hammer SM, et al. Antiretroviral therapy in adults updated recommendations of the international AIDS society - USA panel. J Am Med Assoc 2000;283:381-390. [http://dx.doi.org/10.1001/jama.283.3.381]

55. Hogg RS, Yip B, Chan K, et al. Non-adherence to triple combination is predictive of AIDS progression and death in HIV positive men and women. 7th Conference on Retroviruses and Opportunistic Infections, San Francisco, California, USA, 30 January - 2 February 2000

56. Boden D, Hurley A, Zhang L, et al. HIV-1 drug resistance in newly infected individuals. I Am Med Assoc 1999;282:1135-1141. [http://dx.doi. org/10.1001/jama.282.12.1135]

57. Bangsberg DR, Hecht FM, Clague H, et al. Provider estimate and structured patient report of adherence compared with unannounced pill count. 7 th Conference on Retroviruses and Opportunistic Infections, San Francisco, California, USA, 30 January - 2 February 2000

58. Machtinger EL, Bangsberg DR. Adherence to HIV antiretroviral therapy. HIV InSite Knowledge Base Chapter. San Francisco, USA: HIV InSite, 2005. http://hivinsite.ucsf.edu/InSite?page=kb-03-02-09 (accessed 30 August 2011)

59. Carrieri P, Cailleton V, Le Moing V, et al. The dynamic of adherence to highly active antiretroviral therapy: Results from the French national APROCO cohort. Acquir Immune Defic Syndr 2001;21:232-239. [http:// dx.doi.org/10.1097/00042560-200111010-00005]

60. Chesney M, Ickovics J. For the recruitment, adherence and retention committee of the ACTG: Adherence to combination therapy in AIDS clinical trials. Annual Meeting of the AIDS Clinical Trials Group, Washington, DC, USA, 1997.

61. Haynes BF, Pantaleo G, Fauci AS. Towards an understanding of the correlates of protective immunity to HIV infection. Science
1996;271(5247):324-328. [http://dx.doi.org/10.1126/ science.271.5247.324]

62. Becker SL, Holmes CA. AIDS and HIV infection. J Am Podiatr Med Assoc 1990;80:1-2.

63. Zea MC, Reisen CA, Poppen PJ, et al. Disclosure of HIV status and psychological well-being among Latino gay and bisexual men. AIDS \& Behavior 2005;9:15-26. [http://dx.doi.org/10.1007/s10461-005$1678-z]$

64. Klitzman R, Kirshenbaum S, Kittel L, et al. Intricacies and inter-relationships between HIV disclosure and HAART: A qualitative study. AIDS Care 2004;16:628-640. [http://dx.doi.org/10.1080/0 9540120410001716423]

65. Tuldra A, Ferrer MJ, Fumaz CR, et al. Monitoring adherence to HIV therapy. Arch Intern Med 2002;162:1197-1198. [http://dx.doi.org/10.1001/ archinte.159.12.1376]

66. Ormazu JA. Disclosure decision model: determining how and when individuals will self-disclose. Pers Soc Psychol Rev 2000;4:174-185.

67. Eldred LJ, Wu AW, Chaisson RE, et al. Adherence to antiretroviral and pneumocystis prophylaxis in HIV disease. I Acquir Immune Defic Syndr Hum Retrovirol 1998;18:117-125. [http://dx.doi. org/10.1097/00042560-199806010-00003]

68. Horne R, Weinman J. Patients' beliefs about prescribed medicines and their role in adherence to treatment in chronic physical illness. J Psychosom Res 1998;47:555-567.

69. Lerner BH, Gulick RM, Dubler NN. Rethinking nonadherence: historical perspectives on tripledrug therapy for HIV disease. Ann Intern Med 1998;(7):573-578

70. Chesney MA, Ickovics JR, Chambers DB, et al. Self reported adherence to antiretroviral medications among participants in HIV clinical trials: the AACTG adherence instruments. AIDS Care 2000;12:255-266. [http://dx.doi.org/10.1080/09540120050042891]

71. Ammassari A, Murri R, Pezzotti P, et al. Self-reported symptoms and medication side effects influence adherence to highly active antiretroviral therapy in persons with HIV infection. AIDS 2001;28:445-449. [http://dx.doi.org/10.1097/00126334-20011215000006]

72. Carr A, Cooper DA. Adverse effects of antiretroviral therapy. Lancet 2000;356:1423-1430. [http://dx.doi/ org/10.1016/0140-6736(800)902854-3]

73. Chesney MA, Koblin BA, Barresi P, et al. An individually tailored intervention for prevention of HIV infection. Am J Public Health 2003;93:933-938.

74. Arnsten J, Demas P Gourevitch M, et al Adherence and viral load in HIV-infected drug users: Comparison of self-report and medication even monitors (MEMS). 7th Conference on Retroviruses and Opportunistic Infections, San Francisco, California, USA, 30 January - 2 February 2000.

75. Haubrich RH, Little SJ, Currier JS, et al. The value of patient reported adherence to antiretroviral therapy in predicting virologic and immunologic response. AIDS 1999;13:1099-1107.

76. Vitolins MZ, Rand CS, Rapp SR, et al. Measuring . Control Clin Trials 2000;21:188S-194S. 